\title{
Investigation of remanufacturing technologies for medical equipment in the UK and context in which technology can be exported in the developing world
}

\author{
Kingsley Oturu ${ }^{1}$ D $\cdot$ WL ljomah $^{1} \cdot$ Alexander Broeksmit $^{1} \cdot$ Daniel Hernandez Reig $^{1}$ • \\ Matthew Millar ${ }^{1} \cdot$ Craig Peacock $^{1} \cdot$ Jacob Rodger $^{1}$
}

Received: 7 October 2020 / Accepted: 10 June 2021/ Published online: 4 August 2021

(C) The Author(s) 2021

\begin{abstract}
With the lack of access to medical equipment clear to see throughout the developing world in comparison to the developed world, solutions to bridge the gap are key to reducing the inequality of healthcare between the two. It has been identified that healthcare systems in developed countries have a rapid turnover of medical imaging equipment (X-ray, MRI, CT scanners, etc.) due to the high rate of technological advancement. There is therefore a stockpile of used medical equipment that could still be of use in developing countries thanks to remanufacturing. The aim of this paper is to investigate the applicability of remanufacturing medical equipment with the intent of supplying said equipment to the countries that need it. This investigation provides a clearer picture of the feasibility of using remanufacture to supply developing countries with the medical imaging devices they require. This is done through studying current remanufacturing processes carried out in developed countries, whether that be directly through OEMs or third parties, and assessing how the methods used could be applied to developing countries. It is identified that remanufacturing practices could benefit developing countries not only by increasing access to diagnostic equipment, but also society as a whole by creating jobs for instance. A key remanufacturing stage that should initially be focused on is inspection as it helps to filter and select the medical devices that are most suited for the remanufacturing process.
\end{abstract}

Keywords Remanufacturing · Medical devices · Developing countries

Kingsley Oturu

Kingsley.oturu@strath.ac.uk 


\section{Introduction}

The world of manufacturing is continually growing and advancing; consistently producing new methods of production and new products to use. The ever increasing economic and ecological pressures of manufacturing has led to the desire to remanufacture products in an attempt to restore them to their previous working condition. Remanufacturing is the process of returning a used product to at least Original Equipment Manufacturer (OEM) performance specification from the customers' perspective and giving the resultant product a warranty that is at least equal to that of a newly manufactured equivalent. It is a method of rejuvenating a chosen product to at least its original condition [36]. The possibility of remanufacturing has led to remanufactured products being restored to a better working condition than the original and the newly remanufactured part is able to be accredited with a renewed warranty $[15,26]$. A remanufactured product may exceed the original manufacturer's warranty as new advanced parts may be introduced in the process. Remanufacturing is currently being employed and developed in fields such as Aerospace, Oil and Gas and Automotive due to its ability to be incredibly cost effective for high value parts. Development and research into expanding the capabilities of remanufacturing are steadily reaching outwards to fields such as medical and the sporting world.

However, the opportunity to remanufacture products is not equally balanced worldwide and appears to be a privilege of the developed world. The quality and feasibility of remanufacturing in the developing world consistently reflects the standards of living in these countries. Therefore, the combination of a lower standard of living in the developing world and the continuous motivation to improve manufactured products in the developed world, leaves the possibility of bridging the product gap between these two worlds. Developments in medical remanufacturing become increasingly valuable to the developing world due to the wildly different standards of health. For example, a World Health Organisation report from 2018 stated that [47]:

In contrast to other world regions, the proportions of cancer deaths in Asia and in Africa (57.3\% and $7.3 \%$, respectively) are higher than the proportions of incident cases $(48.4 \%$ and $5.8 \%$, respectively), because these regions have a higher frequency of certain cancer types associated with poorer prognosis and higher mortality rates, in addition to limited access to timely diagnosis and treatment in many countries

This suggests that the inability to establish appropriate and sophisticated health care through technology is leading to a larger mortality rate percentage compared to more developed countries. The disparagement of medical funding and available medical equipment worldwide may be a major contributing factor, and remanufacturing could contribute to a vital boost to medical treatments worldwide.

It is worth noting that the burden of disease is different in diverse contexts with infectious diseases high in developing countries while chronic long-term diseases such as cancer and heart disease are more prevalent in the developed world.

\section{Aim}

The aim of this paper is to investigate the applicability of remanufacturing medical equipment with the intent of supplying said equipment to the countries that need it. An extensive literature review is undertaken which provides insight into the basis of remanufacturing compared to recycling and repairing equipment. Further details of the literature review methodology are 
shown in Section 3. The remanufacturing process can be broken down to six common characteristics each with a vast and diverse background and contribution to the final product. This paper explores the process of inspection and how it is key in the remanufacturing of medical equipment as well as addressing areas of development. The study also examines the possible remanufacturing opportunities in the medical field with an in-depth discussion of the knowledge gaps. Finally, literary based recommendations and conclusions will be made on what developments should be focussed on and how these developments can be completed.

\section{Methodology}

The literature searches were conducted using the databases of MEDLINE, SCOPUS, Google Scholar search engine and University of Strathclyde online database of journals. The databases provided a broad view of related articles from leading scientific journals. Key words in the literature search were based on aims of the paper.

By means of the already mentioned key words ("remanufacturing", "medical devices" and "developing countries") and following such methodology the literature review was narrowed down in the next order:

- Medical data and medical devices statistics.

- Medical devices \& remanufacturing.

- Remanufacturing \& developing countries (with Nigeria emphasis).

- Remanufacture engineering.

To compose this paper the initial research into the topics provided greater perspective on current research and information available. After analysing web resources and journals on remanufacturing of medical devices, report findings and data were collected and analysed systematically. The research was tailored into specific areas where information was lacking, and where further research was required. After analysing the collective findings, the direction of this paper was finalised and conclusions made.

The reference lists of selected articles were also reviewed for further articles. Relevant articles from these lists were then reviewed. Thousands of potential articles were identified for the paper. Abstracts were checked initially. If they suggested that the article was relevant then the whole article was reviewed. The review focused on studies that provided insight on the remanufacturing of medical equipment and the context in which they take place. The review also focused on contemporary studies conducted mainly within the last two decades. Combinations of various keywords were used to limit searches using Boolean 'or' and 'and' reasoning. Both preliminary and secondary literatures were considered as well as studies of any design that dealt with medical equipment and remanufacture. Literatures selected were mainly restricted to those in English.

\section{Literature review}

\section{Demand in developing countries}

When evaluating the possibility of remanufacturing medical devices, it is important to initially evaluate the state of the medical devices that will likely be available for remanufacture in these 
countries. It is also important to understand the medical issues that can be combatted and therefore the specific medical devices that would be the most effective in the third world.

A report on worldwide health statistics discusses how child mortality worldwide is reducing consistently every year. Medical improvements at all stages of pregnancy and early living have led to the lowest worldwide child mortality rates in our history. However, the rate of decrease is not consistent, and this leaves countries within the third world to be consistently lagging. As previously mentioned, a plethora of factors affect overall medical care within the third world, and this again leads to differing rates of improvement. In 2017, the UN concluded a study on child mortality rates for children under the age of 5 and concluded that African countries such as Nigeria, Chad, Mali and the Central African Republic had the highest rates of mortality, all between 10 and $13 \%$ [39]. This is incredibly high when compared to the United Kingdom $(0.43 \%)$, United States of America $(0.66 \%)$ and Australia $(0.35 \%)$. Statistically, a high rate of mortality may not necessarily mean that there is a lack of appropriate medical care. There may be other factors such as birth rates and population growth rates that a country would exhibit. Cultural norms of trying to have more children in the developing world may mean that infant mortality will be higher in developing countries and thus creates a cycle. Historically, families in now more developed places such as the UK or USA would have had more children with higher infant mortality rates. It is from this reflection of the past that we can begin to understand that reducing child mortality is possible through appropriate medical and financial developments. This is an area that remanufacturing could enable the availability of crucial medical equipment to these countries where it would not otherwise be possible.

Another study from the World Health Organisation (WHO) also discusses how mortality rates remain high in these developing countries due to the lack of accessibility in these developing regions [43, 44]. This is described as medical coverage and is defined as the percentage of people that have access to appropriate medical treatments compared to the percentage of people who need medical treatments. Therefore, a higher coverage gap means a larger requirement for medical improvements in these areas. Similar to the previous report, developing countries exhibit the largest gaps in medical coverage (from 55 to $85 \%$ ) which in turn leads to higher volumes of preventable deaths. The study suggests that countries with decreasing coverage gaps have recently improved neonatal and maternal care (30\% decrease) and appropriate family planning (20\% decrease). This demonstrates that improvements in these areas could lead to improvements in overall healthcare standards and could be a contributing factor to overall improvements to livings standards in these areas.

From these two studies improving the healthcare given to children and pregnant mothers can have a huge benefit on overall living standards. When applying this information to a manufacturing and equipment standpoint, it appears that important prenatal screening and medical care can influence child mortality. When it comes to medical equipment used to improve this sector, ultrasound machines and other forms of sonography are required.

The large gaps in the standards of medical care are continually growing due to the differing speeds of development between developed and developing countries. This implies that a device that could be deemed not "state-of-the-art" in the developed countries, may vastly improve the standards of medical care possible in regions of the developing world. Accessibility to these machines play a large factor in medical standards and is down to the initial investment costs of sourcing these important scanning devices as well as maintaining them. For context, a 2018 article into availability of magnetic resonance imaging through Central and West Africa collected the following data on the distribution of MRI scanners in Table 1 [33]: 
It can be seen that the availability of these scanners is incredibly sparse with the majority of them being in Nigeria. When evaluating Nigeria by itself, it must be noted that the majority of these scanners are located in highly populated and more developed areas such as Lagos (14 MRI units) and the capital city, Abuja (10 Units). It is also noted that these MRI units are predominantly owned by the private health sector in these regions, accounting for $63 \%$ of these machines. For comparative analysis a table of the total MRI units per million population from selected countries, considered to be better developed, is shown below in Table 2:

The study concludes that foreign investment in the African private healthcare system is growing and so is interest in development in overall medical standards. However, these developments have only been for a selected population. Standard healthcare and medical insurance will not cover the costly use of these MRI machines leaving them to only be used by the privileged and not by the majority who require them too. From the survey it can be noted that increasing total GDP of a country is more likely to lead to investment in central concerns such as public medical care. It is for these reasons that the ability to remanufacture medical equipment for developing countries is not only beneficial for overall health care standard, but the evidence supports the idea that increasing public health leads to a larger working population leading to an increase in overall GDP which in turn will lead to greater investment in the people of these countries. The following sections therefore address how medical devices such as scanners and imaging machines are being remanufactured in the developed world. This is then taken forward to address its use and implementation in the developing world through various methods.

\section{Medical device remanufacture in the developed world}

Before delving too much into the state of remanufacturing in third world countries, it is important to first identify what is feasible and currently being done in the developed world,

Table 1 Breakdown of MRI units across Western and Central Africa [33]

\begin{tabular}{|c|c|c|c|c|c|}
\hline Country & $\begin{array}{l}\text { Population } \\
\text { (2017) }\end{array}$ & $\begin{array}{l}\text { MRI } \\
\text { units }\end{array}$ & $\begin{array}{l}\text { Approx per million } \\
\text { population }\end{array}$ & $\begin{array}{l}\text { GDP per } \\
\text { capita }\end{array}$ & $\begin{array}{l}\text { Human development } \\
\text { index }\end{array}$ \\
\hline Nigeria & $191,835,936$ & 58 & 0.3 & $2,929.525$ & 0.514 \\
\hline Ghana & $28,656,723$ & 14 & 0.48 & $1,384.354$ & 0.579 \\
\hline Mauritania & $4,266,488$ & 3 & 0.77 & $1,197.121$ & 0.506 \\
\hline Ivory Coast & $23,815,886$ & 2 & 0.08 & $1,425.056$ & 0.462 \\
\hline Senegal & $16,054,275$ & 2 & 0.14 & 945.863 & 0.466 \\
\hline Guinea & $13,290,659$ & 1 & 0.07 & 519.173 & 0.411 \\
\hline Burkina Faso & $19,173,332$ & 1 & 0.06 & 644.502 & 0.402 \\
\hline Togo & $7,691,915$ & 1 & 0.15 & 586.301 & 0.484 \\
\hline Gambia & $2,120,418$ & 1 & 0.54 & 435.452 & 0.441 \\
\hline Cape Verde & 533,468 & 1 & 2.00 & $3,057.916$ & 0.646 \\
\hline $\begin{array}{l}\text { Benin } \\
\text { Republic }\end{array}$ & $11,458,611$ & 0 & 0.00 & 814.360 & 0.480 \\
\hline Mali & $18,689,966$ & 0 & 0.00 & 844.274 & 0.419 \\
\hline Liberia & $4,730,437$ & 0 & 0.00 & 478.681 & 0.430 \\
\hline Niger & $21,563,607$ & 0 & 0.00 & 412.797 & 0.348 \\
\hline Sierra Leone & $6,732,899$ & 0 & 0.00 & 635.892 & 0.413 \\
\hline $\begin{array}{l}\text { Guinea } \\
\text { Bissau }\end{array}$ & $1,932,871$ & NA & NA & 624.671 & 0.420 \\
\hline TOTAL & & 83 & & & \\
\hline
\end{tabular}


Table 2 Distribution of MRI units globally [33]

\begin{tabular}{lcc}
\hline Country & MRI units (Approx. /Million) & GDP per capita \\
\hline Japan & 51.67 & 32,477 \\
USA & 38.96 & 56,116 \\
South Korea & 26.47 & 27,222 \\
Spain & 15.30 & 25,832 \\
France & 12.59 & 36,206 \\
Portugal & 9.90 & 19,222 \\
Turkey & 9.81 & 9,126 \\
New Zealand & 9.62 & 37,808 \\
Canada & 9.48 & 43,249 \\
Qatar & 9.22 & 73,653 \\
Saudi Arabia & 0.97 & 20,482 \\
Mexico & 2.25 & 9,008 \\
Serbia & 6.20 & 5,235 \\
Libya & 5.16 & 4,642 \\
Israel & 4.21 & 35,728 \\
Uruguay & 2.94 & 15,574 \\
Tunisia & 2.00 & 3,873 \\
Morocco & 0.36 & 3,004 \\
Egypt & 2.00 & 3,615 \\
South Africa & 2.90 & 5,724 \\
\hline
\end{tabular}

especially when it comes to healthcare related imaging products (in this case scanners, X-ray and MRI machines, etc.). Rapid technological innovation is the main reason why many highend medical devices are frequently replaced, as better equipment leads to better diagnosis and treatment for patients [22-25]. The turnover of these products is therefore relatively high, but this however does not make the "older" equipment totally useless or obsolete.

In developed countries medical scans tend to be used as part of regular medical processes and the availability of medical scans is greater than ever before. A study from the House of Commons in 2019 states that in England alone there are over 20,000 uses of Ultrasound scanners daily in diagnostic tests. There are also roughly 10,000 MRI scans daily and over 17,000 CT scans daily [17]. These statistics are also only representative of NHS statistics and do not consider private medical care. A study into the renewal of radiological equipment by the European Society of Radiology states that these medical scanning devices are expected to have a lifecycle ranging from 8 to 12 years based upon the usage and the likelihood in equipment breakthroughs [7]. The study also recommends that all equipment be evaluated and possibly updated every 5 years leading to the disposal of a lot of scanning equipment that could be rejuvenated and reused in developing countries.

According to the Centre for Remanufacturing \& Reuse (CRR), the National Health Service (NHS) does not currently make use of remanufactured medical imaging systems and buys all their equipment new [37]. There is therefore a potential stockpile of used equipment that could be remanufactured for other markets. A company which is actively remanufacturing used products is Philips Healthcare Refurbished Systems (PHRS), a part of the parent company Koninklijke Philips N.V., best known for its electronics manufacturing which includes many types of medical devices. One group of devices that PHRS remanufacture are Interventional XRay (IXR) systems such as the Diamond Select Allura Xper R7 FD20/10 IXR, depicted below in Fig. 1, which has been carefully designed for reliability and modularity making it more straightforward for remanufacture [21]. It was previously addressed that there is a major demand for ultrasound and other imaging machine in a bit to help prevent infant mortalities. 
While the IXR system remanufactured by PHRS is not an ultrasound device it is still of the same category of imaging devices. Therefore, it perfectly illustrates how the remanufacturing industry does already work with high end complex products such as this. From research it was addressed that there was a lack of companies and literature surrounding the remanufacture of ultrasound imaging devices and so presents a gap in knowledge to be addressed in the future.

PHRS additionally have an active refurbishment structure in place to collect pre-owned machines from hospitals and harvest components. This strategy is implemented to comply with European Union (EU) regulations on the disposal of waste electrical and electronic equipment (WEEE), put in place to make manufacturers more responsible for the disposal and recovery of their used products. It is thanks to such regulations that the incentive to remanufacture has become more appealing to producers in recent years $[42,48]$. The used items collected by PHRS then go through the phases of remanufacturing as mentioned previously with repairs specially tailored for the new buyers' requirements. This shows that machines that are no longer in use could be remanufactured back to working condition and tailored for the specific needs of third world countries. This could possibly mean just a "base" remanufacture (without any upgrades) to keep costs of the remanufactured product low. With regards to costs, PHRS sell their remanufactured equipment at a reduced rate of 25 to $40 \%$ cheaper compared to their brand-new products, with the same guarantees in regard to quality and warranty [21]. This is in line with a statement made by GE Healthcare and Siemens, other manufacturers of medical devices, who state that remanufactured medical equipment can cost respectively 20 to 50 and $30 \%$ less than new products [16, 37].

This is a considerable saving and makes the products more accessible for healthcare institutions. Another advantage of the remanufacturing process here is that the lifespan of the IXR systems can be extended by 5-10 years in developed countries thanks to remanufacture [21]. This could be considerably more in developing countries as there is not as big an incentive to frequently upgrade equipment. It is evident that there is definitely a gap in the market to explore here as high-end healthcare devices are designed to last more than 20 years with manufacturer support (part replacement, servicing, updates) but are only used every 2 to 3

Fig. 1 Diamond select allura Xper R7 FD20/10 IXR [16]

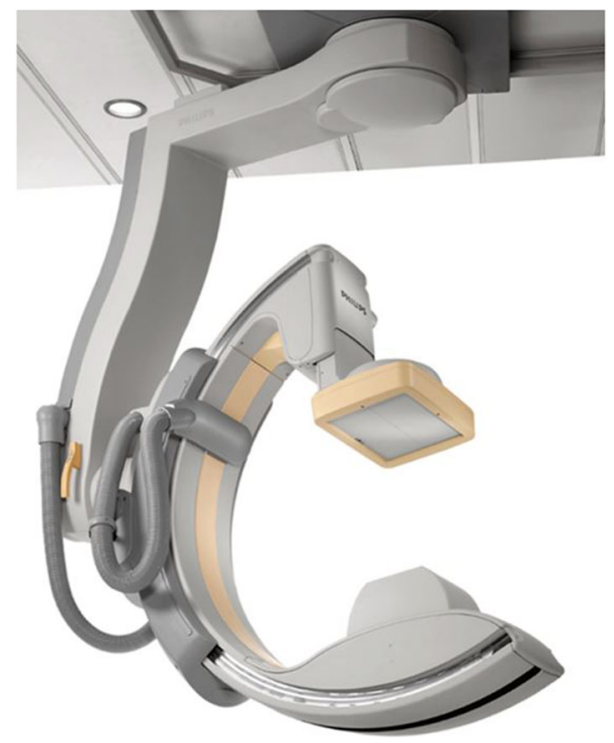


years by hospitals in developed countries as advances in technology occur at a faster rate [16]. An arising problem however is that as the capabilities of devices increase, so does the cost for the implementations into the healthcare institutions which further extends the gap between the developed and developing worlds healthcare conditions.

When it comes to regulations surrounding remanufactured medical imaging equipment, many countries have different standards to follow. GE healthcare remanufacturing regulations state that in the USA, devices and remanufacturers must be FDA registered, in the EU devices must be CE-marked and meet the same requirements as new devices. Countries that prohibit remanufacture of medical devices include those of China, Thailand, Viet Nam and Egypt. $55 \%$ of markets are known to restrict or prohibit purchase of remanufactured devices. Consequences of this are that ethical suppliers are blocked resulting in non-compliant third parties circumventing rules which can have consequences on quality and safety of device and therefore medical care again extending the gap between worlds [16].

\section{Remanufacture by OEMs and third parties}

The remanufacturing of high-end medical devices such as diagnostic equipment is currently being carried out by both original equipment manufacturers (OEM) as well as by other third parties and is driven by the need for more affordable systems for the end user.

OEMs are actively seeking to increase the remanufacture of mostly their high-end devices through trade-in schemes as it presents a good opportunity for additional revenue along with advertising ability $[14,35,38,40]$. The previously discussed Philips Healthcare Refurbished Systems (PHRS) are an example of an OEM who is remanufacturing their products. The decision to remanufacture devices also has implications on its design. Some design choices that are beneficial for manufacturing efficiency are not necessarily beneficial for remanufacture. Using irreversible snap-fittings for device covers for instance decreases production time and costs during manufacture but are a hindrance to remanufacturing the device and increase the cost of remanufacture [3]. OEMs such as Siemens are a prime example of companies who are making large strides in remanufacturing becoming a large source of income. When it comes to Siemens, a "Proven Excellence" certificate is delivered for remanufactured products which guarantees them to have the same warranty as a new system. The processes at competitors are very similar with some companies offering different levels of remanufacturing with different warranty promises. GE healthcare offers 3 levels of warranty with the most basic remanufacture only bringing back the device to working condition with limited warranty [16]. This could be beneficial for developing countries as the price of such devices is considerably lower but could be disapproved of as the perception could be that they are getting an inferior product. The actual remanufacturing process undertaken by these companies is addressed in the implementation section and shows how they typically follow the same process and trends as set out in the literature.

Another way medical that devices can be remanufactured is thanks to third parties who purchase used equipment from hospitals. As previously mentioned, In the UK, the NHS does not sell their used equipment directly and uses auction platforms instead. There are two types of third parties which seek to purchase used devices, those who will actively remanufacture them and those who will simply sell them on for profit (brokers). It is the first type which is of interest here and the work they carry out on the used devices is very similar to the one carried out by OEMs. This involves all key steps of the remanufacturing process, which are discussed in a later section, thanks to the use of trained engineers with a high level of expertise. Most of 
the warranties given to devices remanufactured by third parties are however considerably shorter than those guaranteed by OEMs and range between 30 days to a year in most cases [16]. Third party remanufacture is an interesting option for remanufacture in third world countries as it would allow the work to be done locally and would facilitate servicing during the products use. This would also create jobs in countries where unemployment is high and reduce costs as it is cheaper than buying remanufactured devices from OEMs. A hurdle for this though is the lack of skilled workers capable of carrying out the remanufacture in such countries which is linked to the large portion of non-functioning medical devices there (up to $40 \%$ compared to $1 \%$ in developed countries) [14].

\section{Remanufacturing in developing countries}

As Eze et al. [8] highlights, the remanufacturing industry might be an affordable solution for developing countries to improve their current healthcare systems. The shortage of state-of-theart medical equipment, including essentials such as oxygen masks and syringes [46], is one of the major shortfalls in developing countries. Due to this inability to supply modern day medical standards, higher mortality rates exist for diseases that require to be monitored or treated by using specific technology such as diarrhoeal diseases and preterm births [8].

The World Health Organisation (WHO) emphasises that the relocation of large multinational companies to developing countries, with the aims to take advantage of lower production costs, limit the flourishing of the local production of medical equipment. Hence, the acquisition of new technology is still dependant on donations from the first world (up to $80 \%$ in some countries).

Also, the WHO's research shows that roughly $50 \%$ of developing countries' medical equipment is malfunctioning, misused or not properly maintained. According to the study, this might be a consequence of the lack of capacity to make the public healthcare system a national priority leading to degradation of equipment and investment elsewhere $[45,46]$.

Whereas some production companies aim to manufacture low-cost medical equipment [6], Eze et al. [8] encourage the implementation and development of remanufacturing within the industry in order to drive the local production of medical supplies and equipment. This remanufacturing could even be run by OEMs due to the lower costs of remanufacturing compared to manufacturing new equipment. Implementation of remanufacture in developing countries has huge economic and environmental potential [11-13]. In Ghana a huge gap has been identified where a huge majority of automotive parts and machines are currently imported to the country and sold "as is" [10]. These parts are generally used until failure and then sent to landfill. The opportunity here is for incoming used products to be remanufactured and given new warranties for customers thus extending the life of the products while minimising waste. Ideally, the remanufacture would take place in collaboration with the OEMs to ensure that products are being remanufactured to their original standard of quality or indeed to be of a higher quality than the original product. Although this would require a significant capital investment, it would provide many jobs for people in Ghana. These new businesses would be tax paying and in turn would significantly boost the country's economy. There is potential for similar systems to be put in place in other African countries and other developing countries in the world. If this system is paved to work well with automotive and machine parts, then there is no reason that these methods cannot be adopted to remanufacture second hand medical equipment in developing countries. 
Regarding remanufactured medical equipment regulations, Eze et al. [8] point out that they are 'inexistent or weak' in developing countries. Therefore, if remanufacturing is to be fully embraced regulations will need to be developed and employed to ensure safety and quality is upheld. According to the evaluation of the strengths, weaknesses, opportunities and threats (SWOT) related to the remanufacture industry carried out by D'Adamo \& Rosa [5], suggest that remanufacturing costs of medical equipment could be double that of aerospace or automotive cases, as can be seen in the Fig. 2 below. This could be a potential drawback for investors looking to expand the sector in new countries. Two of the strengths mentioned of this new field are the job creation and the potential profitability from this new market. This may be a motivating factor for developing countries with intentions to place themselves at the heart of a new business sector as well as solving a fundamental problem in the third world.

Government regulations are minimally required in order to promote the use of remanufactured medical equipment due to the predominant external investment (Fig. 3). This can lead to preferring remanufactured devices over new ones due to the accessibility and reasoning behind decommission of current medical devices [5]. Additionally, the use of second-hand items seems to be more normalised within the society in developing countries due to the limited availability of products [32]. Another challenge is in obtaining cores that are crucial for the remanufacturing process. The critical role of the utilisation of cores in the remanufacturing process is demonstrated in Fig. 4.

Taking Nigeria as a reference, the medical device market in developing countries has been growing in the last few years and is forecasted to continue to grow. Large volumes of consumables are being utilised in Nigeria, with the majority being imported (36\% China, $43 \%$ Europe) [29]. These consumables are crucial in the use of medical equipment in Nigeria and will have an impact on the use of remanufactured products with possible need for ongoing training and support from manufacturers.

Moreover, large quantities of collected end-of-life products are currently being moved across frontiers from developed countries, where the consumption is larger, to developing regions items such as electronic devices are reused and recovered [32]. Hence, logistics should be rearranged in order to redirect the required end-of-life products to the specific regions to be remanufactured.

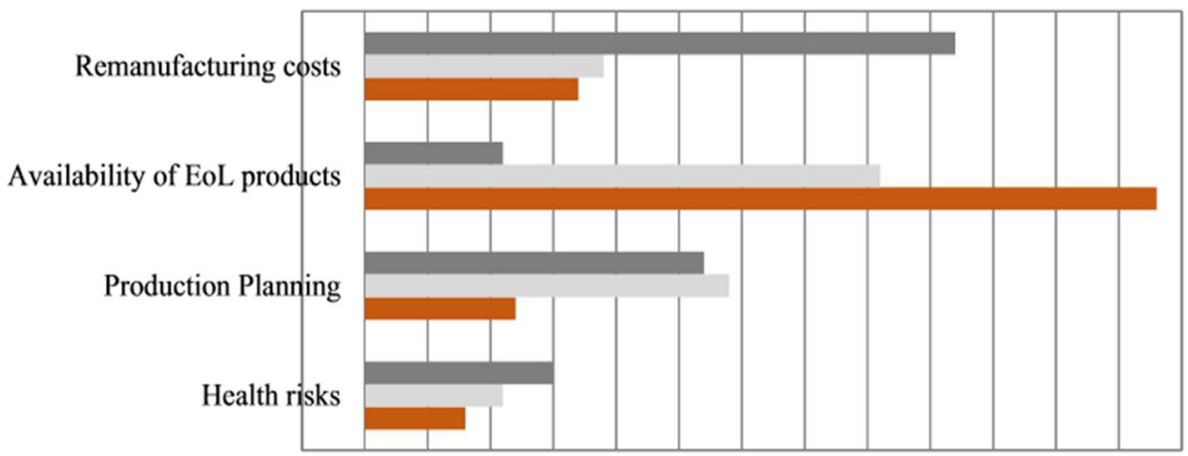

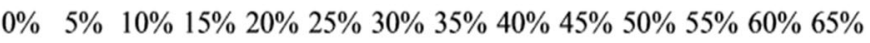

\section{Medical equipments}

Aerospace

automotive

Fig. 2 Weaknesses of remanufacturing [5] 


\section{Implementation of the remanufacturing}

The actual remanufacturing process consists of a number of complex steps with their own individual processes which can require specialized equipment and technologies. Therefore, to address whether or not the remanufacturing of high-end medical imaging equipment According to Ijomah et al. [18], remanufacturing will typically consider a six-step process to fully remanufacture a chosen part or "core":

1. Reception and initial assessment of the "core".

2. Inspection.

3. Cleaning.

4. Stripping and disassembly.

5. Repair.

6. Testing.

Moreover, it must be highlighted that the whole remanufacturing process will depend on the conditions of the received core. According to Ijomah et al. [19, 20], suitable products for remanufacture must consist of a "core" that can be the basis of a restored product. This means, those failed products due to dissolution or dissipation might not be remanufactured, as well as those not possible to disassemble non-destructively.

As previously mentioned, this 6-step process is typically followed by all remanufacturing companies whether it be from OEMs or a third-party company [2, 4, 9, 27]. The process may not be directly followed but the main steps are usually adhered to in some capacity. By looking in depth at the entire remanufacturing process of medical imaging devices at Siemens, five key stages are identified in the OEM to customer loop. They are selection, de-installation, refurbishment, reinstallation and warranty [37]. The selection stage identifies the systems appropriate for remanufacture through inspection and testing. Things checked for here are the availability of spare parts and ability to upgrade to the current software. Once the system has been evaluated and selected, it is then transported to the OEMs remanufacturing factory. The device then undergoes disinfection, cleaning, repainting and the defective components are

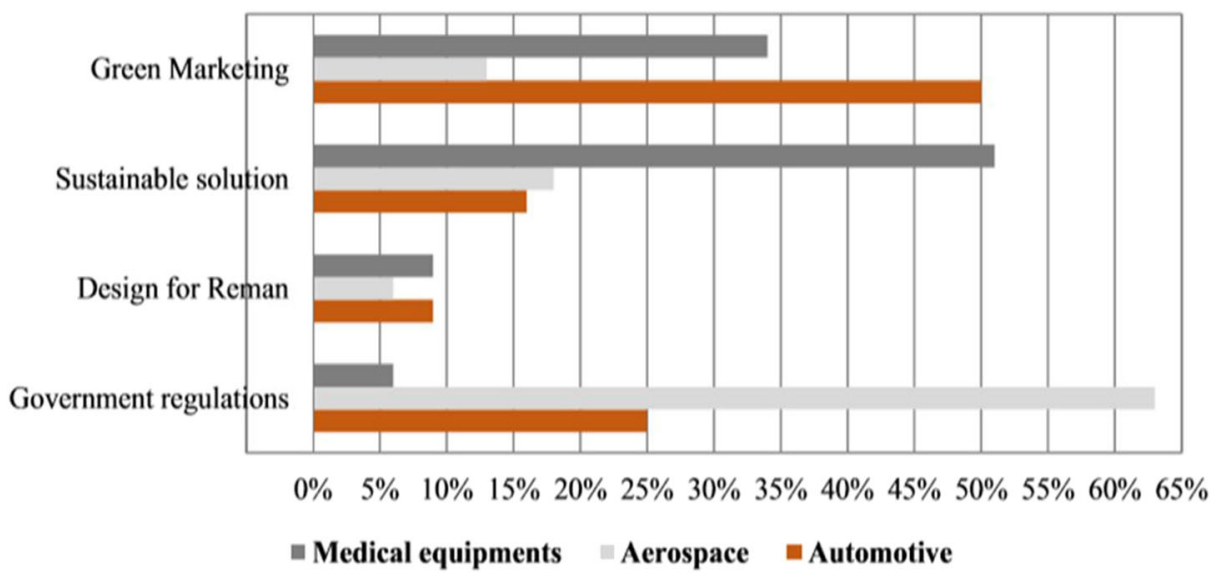

Fig. 3 Opportunities for remanufacturing [5] 


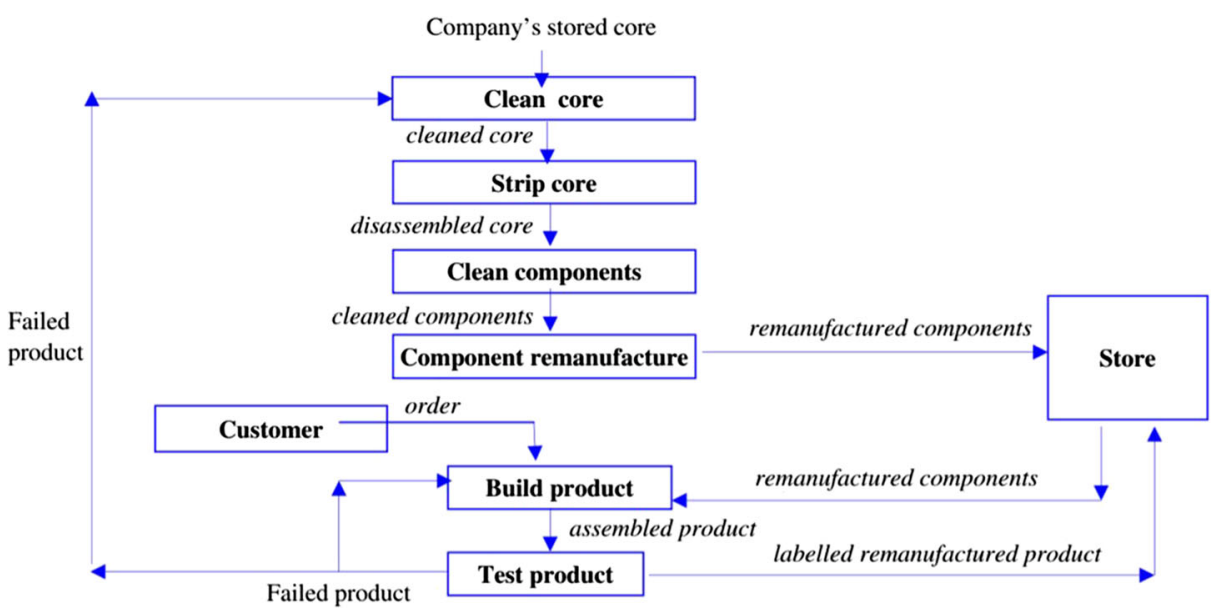

Fig. 4 Remanufacturing process [19]

replaced. The work in the factory is concluded by a mandatory quality acceptance process where the device is tested and inspected before it can be shipped back to customers.

Another company that follows this process is MEDECON Health care who are a third-party company that remanufacture medical imaging systems. This includes a wide range of imagine systems such as X-Ray system, Fluroscopy, Cath labs, CT, MRI, Ultrasound, Mobile X-rays and $\mathrm{C}$-Arms. Their process consists of three steps of selection of imaging system, remanufacturing process and installation and commissioning. However, within these 3 steps in can be seen to comprise all of the other six steps. Firstly, the inspection and grading step is undertaken for selection and initial evaluation of the imaging system. Then the stripping and disassembly enable for the individual inspection of all mechanical and electronic systems. They are evaluated functionally and cosmetically and then remanufactured to exacting standards and manufacturers original specifications. The imaging system is then prepared for operational compatibility and calibration to OEM specifications, during which the hardware and software is updated and upgraded. Then following on from a pass from the certification and the physical checks the system is allowed to move forward to the final stage of reinstallation and commissioning into its designated healthcare institution. MEDECON represents a company in which the remanufacture, redistribution and recommissioning of ultrasound imaging systems is successful. Therefore, it presents a clear opportunity for a source of remanufactured ultrasound imaging systems that could be implemented in developing countries [28].

\section{Inspection}

The inspection and grading step of the remanufacturing process is a key component to address the product/components feasibility to be remanufactured. For medical devices such as scanners and imaging system the process of inspection has a key role to understand the deterioration of these parts of equipment and how they can be remanufactured for further accessible use in the developing world. This process involves inspection of the used products looking at their current condition and quality and to address their remanufacturability status. This is typically done through a complete visual inspection of the product. Inspection times typically vary 
depending on the type of used-product, source from which it originated and the conditions it was used under. Products from the market stream, which is the typical source for medical devices, will have a shorter inspection/grading time requirement than that from the waste stream. This is simply due to the initial conditional quality of market stream products which should not have as severe degradation or damage as that from the waste stream.

It is also worth noting that for used products from the waste stream, not only do they typically require longer inspection time, but also usually require the use of more specialised tools for remanufacture. After the inspection process the components and products which are eligible for remanufacturing, due to their condition assessment, are taken forward. Those unsuitable are classified as scraps and are disposed through recycling or other methods. The remanufacturable components are then further categorised into relevant quality groups where the highest quality products should be given priority for remanufacturing [1, 30, 31]. For high volume manufacturable structures with a simple structure and process the inspection and disassembly of these products would be almost instantaneous. Contrastingly for the large products with complex structure such as those of medical imaging devices discussed, the disassembly and inspection will take place sequentially over a two-stage disassembly line [36]. Selected medical equipment to be remanufactured must be backed by legislation, market and logistic factors in order to ensure feasibility and profitability [41]. Stigma is an important contextual issue in the provision of health care [34]. It needs to be taken into consideration from inspection through to the end of the remanufacture processes. As suggested earlier, while remanufactured medical devices appear not to be widely accepted in developed countries like the UK, this type of stigma does not appear to be the case in developing countries where imported remanufactured products tend to have higher value than local products [16].

To summarise, according to Eze et al. [8]:

- Selected medical equipment to be remanufactured must be only those with recoverable degradation.

- Selected medical equipment to be remanufactured must be only those that can be integrated into current healthcare systems.

- Selected medical equipment must be remanufactured in order to reach the level of upgrade of the latest technology.

\section{Conclusions}

This paper aimed to investigate remanufacturing of medical equipment from developed countries and how it may be supplied to developing countries where it is needed. This was undertaken employing a systematic literature review methodology. In terms of creating the right environment for remanufacture to flourish, it is suggested that 'reputable manufacturers' might be attracted by an advantageous national market, and with these large OEMs working in developing countries, the supply of core information and spare parts would be facilitated. Also, training and teaching of related subjects would be beneficial in order to provide skilled labour.

In other words, most of the responsibility to make the implementation of the remanufacture industry possible devolves upon governments. Developed countries currently have financial and infrastructural privilege, along with the OEM companies, to produce products appropriate for remanufacture and to carry out the repairs themselves. There is then a huge opportunity for this remanufactured equipment to be given to developing countries, be that through donation 
or sale, so long as information is present on where specific equipment is required for it to be beneficial to the health of the receiving nation.

Third party remanufacture is an interesting option for remanufacture in developing countries as it would allow the work to be done locally and would facilitate servicing during the products use. This would also create jobs in countries where unemployment is high and reduce costs as it is cheaper than buying remanufactured devices from OEMs. A hurdle for this though is the lack of skilled workers capable of carrying out the remanufacture in such countries which is linked to the large portion of non-functioning medical devices there.

Another potential option is for OEMs to set up remanufacturing facilities in developing countries. This would reduce unemployment and costs in a similar way to third party remanufacturing, but the OEM's would be able to provide specific training. This could quickly build a skilled work force which could effectively remanufacture medical equipment and provide new warranties and guarantees to the customer. A hurdle with this approach would be that the workforce would be skilled but only in remanufacturing of specific machines and equipment.

Another approach could be that the remanufacturing could be conducted by a third-party company in the developing country. The businesses being local to the developing countries would further reduce unemployment and allow them to carry out work on equipment from multiple manufacturers. In this case, the OEM's could act as consultants to advise on the latest versions of products and even sell spare parts to the remanufacturers.

With developing countries having a high demand for remanufactured medical devices a preferable approach, could be for OEMs or Third-party remanufacturers to remanufacture medical equipment in developed countries and export these to developing countries. This will help to create green jobs in the developed countries and provide access to technical expertise and greater assurance of performance standards (especially with OEMs involvement).

However, there are no easy answers. It is important that international collaborations and partnerships between developed and developing countries are encouraged. This could lead to shared learning and knowledge transfer, transfer of professional expertise, local capacity building, sharing of resources, cross fertilisation of ideas and contribution to improvement in global health. Through greater partnerships and information sharing, trust is built that provides foundation for adoption of appropriate strategies could be implemented that takes the local and international context into consideration.

If a medical remanufacturing solution can be implemented, particularly with scanning equipment then the developing countries see huge health benefits. One particular benefit could be infant mortality rate decreasing due to more appropriate scanners being available. As was previously mentioned, the inspection stage for scanning equipment is particularly important as image quality is often one of the first things to deteriorate. If imaging equipment can be properly inspected, remanufactured, and given to the places where it is needed most then the general health of those areas can be greatly improved whilst simultaneously reducing unemployment and creating a new skilled workforce.

Future research may be needed on the risk of cannibalization with remanufacture and how it can be managed. Policy research on the operationalisation of remanufacture for value creation and development of remanufacture guidelines/regulations is needed. Theoretical and conceptual research on remanufacturing as well as hypothesis that tests the effectiveness of different business models in remanufacturing is also needed. 
Open Access This article is licensed under a Creative Commons Attribution 4.0 International License, which permits use, sharing, adaptation, distribution and reproduction in any medium or format, as long as you give appropriate credit to the original author(s) and the source, provide a link to the Creative Commons licence, and indicate if changes were made. The images or other third party material in this article are included in the article's Creative Commons licence, unless indicated otherwise in a credit line to the material. If material is not included in the article's Creative Commons licence and your intended use is not permitted by statutory regulation or exceeds the permitted use, you will need to obtain permission directly from the copyright holder. To view a copy of this licence, visit http://creativecommons.org/licenses/by/4.0/.

\section{References}

1. Andrew-Munot M, Ibrahim RN (2013) Remanufacturing processes and its challenges. J Mech Eng Sci (4): 448-495

2. Babu S, Love L, Dehoff R, Peter W, Walkins T, Pannala S (2015) Additive manufacturing of materials: Opportunities and challenges. MRS Bull 40:1154

3. Boorsma N (2016) A design tool for refurbishment: Generating industry specific design rules. TU Delft

4. Brown C, Jacob G, Possolo A, Beauchamp C, Peltz M, Stoudt M, Donmez A (2018) The Effects of Laser Powder Bed Fusion Process Parameters on Material Hardness and Density for Nickel Alloy 625. US Department of Commerce, Barleben

5. D’Adamo I, Rosa P (2016) Remanufacturing in industry: advise from the field. Int J Adv Manuf Technol 86:9-12

6. Eltringham R, Neighbour R (2014) The reality of designing appropriate 'lowcost' medical products for developing countries and their unintended consequence. Appropriate Healthcare Technologies for Low Resource Settings (AHT 2014). London

7. European Society of Radiology (2014) Renewal of radiological equipment. ESR

8. Eze S, Ijomah WL, Wong TC (2019) Accessing medical equipment in developing countries through remanufacturing. J Remanuf 9:207-233

9. Brodmann F (2007) Cold spray process parameters: powders. In: The Cold Spray Materials Deposition Process. Woodhead Publishing Series in Metals and Surface Engineering, pp 105-116

10. Fiagbe Y, Asafo-Adjaye MK (2013) Potential of remanufacturing industry in Ghana. In: The GhIE 2013 Conference, March 2013, Takoradi. Ghana, pp 1-14

11. Ford (n.d.) Ford develops high-tech plasma process that can save an engine from the scrapyard while reducing co2 emissions. Retrieved March 16, 2019, from https://media.ford.com/content/fordmedia/feu/en/ news/2015/12/02/ford-develops-high-tech-plasma-process-that-can-save-an-engine-f.html

12. Ford S, Despeisse M (2016) Additive manufacturing and sustainability: an exploratory study of the advantages and challenges. J Clean Prod 137:1573-1587

13. Kim GE, Champagne V, Trexler M, Sohn Y (2011) Processing nanostructured metal and metal-matrix coatings by thermal and cold spraying. In: Whang SH (ed) Nanostructured Metals and Alloys. Woodhead Publishing Series in Metals and Surface Engineering, pp 615-662

14. Kane G, Bakker C, Balkendende R (2018) Towards design strategies for circular medical products. Resour Conserv Recycl 135:38-47

15. Gibson I, Rosen D, Stucker B (2015) Directed energy deposition processes. Additive manufacturing technologies. Springer, New York, pp 245-268

16. Healthcare G (2009) Medical device remanufacturing. APEC Singapore, Singapore

17. House of Commons UK Parliament (2020) NHS Key Statistics: England, February 2020, Research Briefing Paper Number 7281, House of Commons, England

18. Ijomah WL, Bennet J, Pearce J (1999) Remanufacturing: Evidence of Environmentally Conscious Business Practice in the UK. First international symposium on environmentally conscious design and inverse manufacturing. Tokyo, Japan

19. Ijomah WL, Childe S, McMahon C (2004) Remanufacturing: a key strategy for sustainable development. Design and Manufacture for Sustainable Development, pp 51-63

20. Ijomah WL, McMahon C, Hammond G, Newman S (2007) Development of robust designforremanufacturing guidelines to further the aims of sustainable development. Int J Prod Res 45(18-19): 4513-4536

21. Jensen J, Prendeville S, Bocken N, Peck D (2019) Creating sustainable value through remanufacturing: Three industry cases. J Clean Prod 218:304-314 
22. Jones J, McNutt P, Tosi R, Perry C, Wimpenny D (2012) Remanufacture of turbine blades by laser cladding, machining and in-process scanning in a single machine. 23rd Annual International Solid Freeform Fabrication Symposium, 2012 Austin, TX, USA: University of Texas, pp 821-827

23. Langfeng Metallic (n.d.) Thermal Spray Technology in remanufacturing engineering, Retrieved 17 May, 2021 from https://www.langfengmetallic.com/d/files/pdf-article/thermal-spray-technology-inremanufacturing-engineering(1).pdf

24. Lei X, Huajun C, Hailong L, Yubo Z (2017) Study on laser cladding remanufacturing process with FeCrNiCu alloy powder for thin-wall impeller blade. Int J Adv Manuf Technol 90:1383-1392

25. Leino M, Pekkarinen J, Soukka R (2016) The role of laser additive manufacturing methods of metals in repaid, refurbishment and remanufacturing - enabling the circular economy. Phys Procedia 83:752-760

26. Loughborough University (n.d.) Directed Energy Deposition. (Loughborough University) Retrieved March 16, 2019, from https://www.lboro.ac.uk/research/amrg/about/the7categoriesofadditivemanufacturing/ directedenergydeposition/

27. Matsumoto M, Yang S, Martinsen K, Kainuma Y (2016) Trends and research challenges in remanufacturing. Int J Precis Eng Manuf-Green Technol 3(1):129-142

28. MEDECON (n.d.) Imaging System Remanufacturing Services. (MEDECON) Retrieved from https://www. medecon.co.uk/imaging-system-remanufacturing-services

29. Medic West Africa (2019) 2019 Nigeria medical device market overview. Informa Markets

30. Aras N, Boyaci T, Verter V (2004) The effect of catergorizing returned products in remanufacturing. IIE Transitions 4(36):319-331

31. Aras N, Verter V, Boyaci T (2006) Coordination and priority decisions in hybrid manufacturing/ remanufacturing systems. Prod Oper Manag 15(4):528-543

32. Nnorom IC, Osibanjo O (2010) Overview of prospects in adopting remanufacturing of end-of-life electronic products in the developing countries. Int J Innov Manag Technol 1(3):328-338

33. Ogbole GI, Adeyomoye AO, Badu-Peprah A, Mensah Y, Nzeh DA (2018) Survey of magnetic resonance imaging availability in West Africa. Pan Afr Med J (30):240

34. Oturu K (2011) Stigma in access to HIV treatment in African Countries: The importance of social connections. Grounded Theory Rev 10(2):63-90

35. Paterson D, Ijomah WL, Windmill J (2017) End-of-life decision tool with emphasis on remanufacturing. J Clean Prod:653-664

36. Steinhilper R (1998) Remanufacturing: The ultimate form of Recycling. Fraunhofer IRB Verlag, Stuttgart

37. Spelman C, Sheerman B (2014) Report: Triple Win - The Social, Economic and Environmental case for Remanufacturing. Policy Connect, England

38. TWI (n.d.) Remanufacture of rail wheels: aurora project. (The Welding Institute) Retrieved March 19, 2019, from https://www.twi-global.com/media-and-events/insights/aurora-project-remanufacture-of-rail-wheels

39. UN Inter-agency Group (2017) Child Mortality. (OurWorldInData) Retrieved from https://ourworldindata. org/child-mortality

40. Walachowicz F, Bensdorf I, Papenfuss U, Zeller C, Graichen A, Navortsky V, Rajvanshi N, Kiener C (2017) Comparative energy, resource and recycling lifecycle analysis of the industrial repair process of gas turbine burners using conventional machining and additive manufacturing. J Ind Ecol 21(S1):S203-S215

41. Walle AH (2008) Remanufacturing marketing strategies and developing countries. J Glob Mark 1(4):75-90

42. Wang J, Prakash S, Joshi Y, Liou F (2002) Laser Aided Part Repair - A review: In 13th Annual Solid Freeform Fabrication Proceedings Symposium, Austin. Texas, pp 57-64

43. World Health Organization (2000) Guidelines for health care equipment donations. Geneva

44. World Health Organisation (2020) Highlights in Health Statistics. World Health Organisation

45. World Health Organization (2008) Towards a WHO model list of essential medical devices. Geneva

46. World Health Organization (2010) Barriers to innovation in the field of medice devices.

47. World Health Organization (2018) Latest global cancer data. WHO, Geneva

48. Yin S, Cavaliere P, Aldwell B, Jenkins R, Liao H, Lupoia W (2018) Cold spray additive manufacturing and repair: Fundamentals and applications. Addit Manuf 21:628-650

Publisher's Note Springer Nature remains neutral with regard to jurisdictional claims in published maps and institutional affiliations. 